

\title{
Treatment of psychiatric comorbidities in patients with epilepsy and intellectual disabilities: Is there a role for the neurologist?
}

\author{
Lance Vincent Watkins a, William Owen Pickrell b, Michael Patrick Kerr c
}

\author{
a Abertawe Bro Morgannwg University Health Board, UK \\ b Neurology and Molecular Neuroscience, Swansea University Medical School, Swansea University, Swansea, \\ UK \\ c Institute of psychological medicine and clinical neuroscience, Cardiff University, UK
}

\section{Abstract}

This paper will explore the nature of psychiatric co-morbidities in people with an intellectual disability (ID) who have epilepsy. The complexity of clinical presentations and associated co-morbidities require thorough assessment utilising both neurological and psychiatric skills. The neurologist plays a central role in the management of epilepsy in people with ID and therefore requires basic competencies in the assessment of neuropsychiatric co-morbidities. This is key to liaison with other specialist services to ensure individuals receive holistic person centred care.

\section{Introduction}

This paper will explore the nature of psychiatric comorbidities in people with an intellectual disability (ID) who have epilepsy. The complexity of clinical presentations and associated comorbidities means that thorough assessment needs both neurological and psychiatric skills.

There is a strong relationship between epilepsy and ID, with the prevalence of epilepsy increasing with severity of ID. A pooled meta-analysis of people with ID estimates an overall prevalence of epilepsy of $22 \%$ [1].

Epilepsy is associated with high levels of comorbidity including a wide range of neurological and psychiatric disorders, and the prevalence of common psychiatric disorders is higher in people with epilepsy than in the general population (Table 1). This includes the population with ID [9], particularly those with active epilepsy [10]. Psychiatric symptoms may be directly linked to seizure activity and present periictally (preictal, ictal, or postictal) or temporally independent of seizure occurrence (interictally).

Neuropsychiatric symptoms have a detrimental impact upon quality of life [2]. They may be explained by common risk factors, underlying anatomical problems, pathological processes that interact both directly and indirectly or the wider impact of epilepsy as a chronic condition [11,12].

A major challenge in attempting to identify the incidence of psychiatric diagnoses for people with epilepsy is sampling a representative population. Sample populations are often derived from specialist epilepsy centers with complex disease and higher rates of neuropsychiatric

comorbidities. Comparing epidemiological studies is difficult, owing to methodological differences, especially when specifically considering epilepsy and ID. Studies are limited with numerous confounding factors, variability in assessment tools, and heterogeneous populations [13].

2. Psychiatric comorbidities in people with epilepsy and ID Up to one-third of people with epilepsy and ID may have a diagnosable psychiatric illness, far above the rate observed in a comparable sample of people with ID alone [14]. A recent systematic review examined neuropsychiatric comorbidities in people with epilepsy and ID. People with epilepsy and ID show higher levels of mood dysregulation, negative mood symptoms, and a lack of empathy [13]. In contrast to other research, there is some evidence that people with epilepsy and ID have less psychiatric symptoms when compared with people with ID alone. Investigators suggest that this may be related to the effect of anticonvulsant medication [15].

There are a number of risk factors for psychiatric comorbidities in people with epilepsy and ID (see Table 2). These include genotype, autistic features, ID severity, and antiepileptic drug (AED) prescription [16]. Both 
seizure severity and frequency have consistently been identified as independent risk factors for psychiatric symptoms in people with epilepsy and ID [14].

Table 1

Evidence for increased prevalence of psychiatric comorbidities in people with epilepsy. (Adapted from Keezer et al., 2016 [2]). "No data.

\begin{tabular}{|c|c|c|c|c|c|}
\hline \multirow[t]{2}{*}{ Authors } & \multirow[t]{2}{*}{ Study } & \multicolumn{4}{|c|}{ Prevalence/odds ratio (95\% d) } \\
\hline & & Anxiety & Depression & $\begin{array}{l}\text { Mood Disorder/Bipolar } \\
\text { affective disorder }\end{array}$ & Psychosis \\
\hline $\begin{array}{l}\text { Tellez-Zenteno et al., } 2007 \\
\text { [3] }\end{array}$ & $\begin{array}{l}\text { Canadian Health Survey (CCHS 1.2), } \\
\text { Community sample. Population with } \\
\text { epilepsy compared with those } \\
\text { without epilepsy. }\end{array}$ & $\begin{array}{l}22.8 \%(14.8-20.9) \text { vs } \\
11.2 \%(10.8-11.7)\end{array}$ & $\begin{array}{l}17.4 \%(10.0-24.9) \text { vs } \\
10.7 \%(10.2-11.2)\end{array}$ & $\begin{array}{l}24.4 \%(16.0-32.8) \text { vs } \\
132(12.7-13.7)\end{array}$ & $\cdot$ \\
\hline Ottman et al., 2011 [4] & $\begin{array}{l}\text { Epilepsy Comorbidities and Health } \\
\text { (EPIC) survey. US. Population survey } \\
\text { of those with lifetime history of epilepsy. }\end{array}$ & $2.0(1.9-2.1)$ & $1.3(1.2-1.4)$ & $2.11(1.82-2.45)$ & • \\
\hline Gaitatzis et al., 2004 [5] & $\begin{array}{l}\text { Cross-sectional population-based study. } \\
\text { Data from UK General practice database. } \\
\text { Adults registered with epilepsy } \\
\text { compared with cohort without epilepsy. }\end{array}$ & $2.0(1.9-2.1)$ & $1.6(1.5-1.8)$ & • & $\begin{array}{l}\text { Schizophrenia } 4.13 \\
(3.05-5.61) \\
\text { Organic psychosis } 3.98 \\
(3.62-4.38)\end{array}$ \\
\hline Rai et al,, 2012 [6] & $\begin{array}{l}\text { The Adult Psychiatric Morbidity Survey } 2007 \text {, } \\
\text { population-based study in England. }\end{array}$ & $2.6(1.5-4.7)$ & $2.7(1.4-5.4)$ & $\cdot$ & $1.7(0.2-15.8)$ \\
\hline $\begin{array}{l}\text { Ettinger et al., } 2004 \text { [7], } \\
\text { Ettinger et al., } 2005 \text { [8] }\end{array}$ & Population-based survey US households. & • & $36.5 \%$ & $12 \%$ ( $49.7 \%$ symptoms) & • \\
\hline
\end{tabular}

People with epilepsy and ID should not be excluded from epilepsy surgical interventions (National Institute for Health and Care Excellence [NICE], CG137) [17]. However, surgical interventions for people with epilepsy and ID remain lower than those without ID[18]. Improvements in behavioral outcomes measures have been observed a year after epilepsy surgery [19]. There is evidence to suggest that epilepsy surgery actually improves both behavioral and cognitive functioning in specific subpopulations of people with epilepsy and ID [16].

The presence of epilepsy in the ID population is also associated with an overall increased risk of behavioral problems [20]. Behavioral changes that commonlymanifest in peoplewith epilepsy and ID include aggression, self-injurious behavior (SIB), disruptive or destructive behavior, and stereotyped behaviors [21]. Behavioral disorders are multifactorial and may be influenced by a wide range of environmental factors. A number of genetic syndromes (Angelman, Cornelia de Lange, Cri du Chat, Fragile X, Prader-Willi, Smith-Magenis) are associated with specific and nonspecific behavioral changes including increased aggression [22]. The severity of intellectual disability itself is associated with awide range of behavioral problems including hyperactivity and stereotypical behavior [14,23]. However, there is evidence to suggest that when confounders are controlled particularly psychiatric comorbidities, increased rates of aggression become statistically insignificant [24].

\section{Table 2}

Risk factors for psychiatric comorbidities for people with epilepsy and people with epilepsy and ID ("evidence in population with ID) (adapted from Torta and Keller, 1999 [12]: Gaitatzis et al., 2004 [5]: van Ool et al., 2016 [13]).

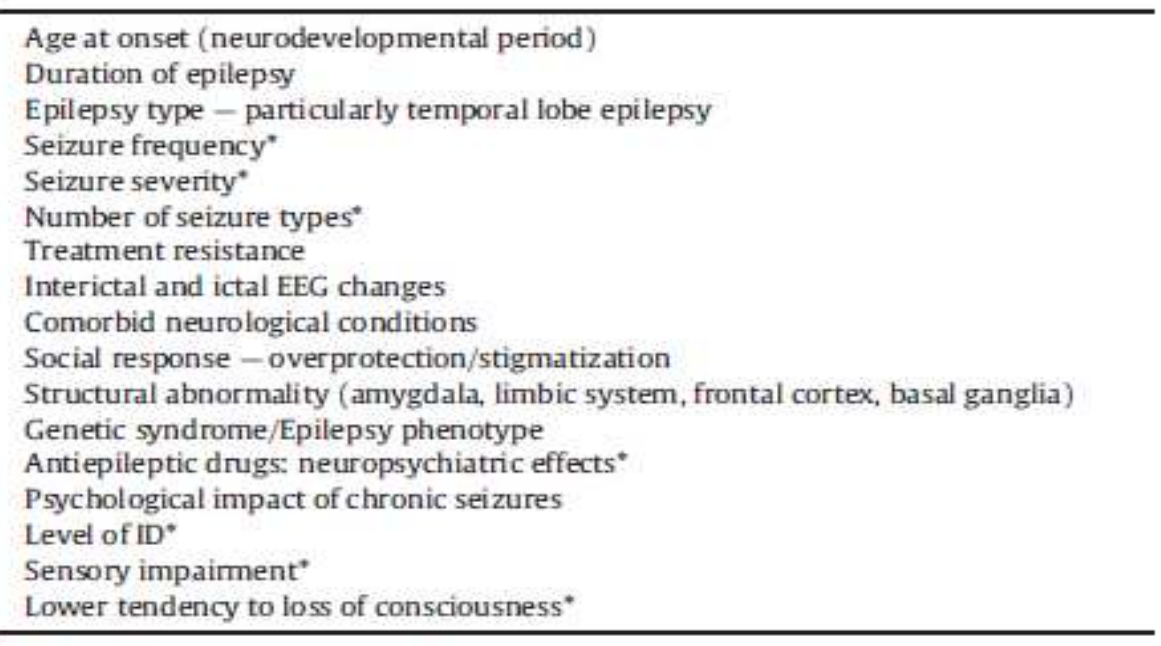




\subsection{Autism}

Autism or autism spectrum disorder (ASD) is a common comorbidity found in association with epilepsy and ID [25] with an estimated prevalence of over $25 \%$ [26]. Autism and ID is associated with increased stereotyped behaviors, SIB, property destruction, aggression, anxiety, irritability, and impaired attention and hyperactivity $[27,28]$. Autism is also associated with an impairment in overall functioning, a known risk factor for behavior problems, suggesting comorbid neurodevelopmental disorders increase the risk of both behaviour problems and psychopathology [29,30].

\subsection{Antiepileptic drugs (AEDs)}

For some individuals, certain AEDs may be associated with adverse neuropsychiatric symptoms (Table 3). However, improvement in seizure control with AEDs can lead to improvement in the cognitive and behavioral effects of epilepsy [32,33]. It has been consistently shown that those individuals with preexisting psychiatric comorbidities are more likely to develop psychiatric adverse effects with AEDs. It is possible that psychiatric side effects may be less common with AEDs that block sodium channels [34].

There is limited evidence evaluating the impact of AEDs in the population with epilepsy and ID. A Cochrane review shows that many of the investigations conducted in this population are low powered, uncontrolled, retrospective, and use unreliable measures of behavior [35]. Behavioral and cognitive side effects of AEDs in this population require further investigation with robust methodology and appropriate assessment measures [35].

Antiepileptic drugs can be used to treat a wide range of psychiatric and behavioral disorders (Table 4). The mood stabilizing properties of valproate, lamotrigine, and carbamazepine have been well-established and they are routinely used as treatment as an acute or prophylactic agent in affective disorders [38]. A systematic review has demonstrated the wide range of psychiatric conditions treated with gabapentin, ranging from anxiety disorders to dependence syndromes [39].

3. Managing psychiatric comorbidities - key components

\subsection{Assessment}

Assessment and treatment of psychiatric comorbidities can be complex because of the wide range of etiologies and comorbidities in people with epilepsy and ID. There are consensus guidelines for the management of behavioral disorder in people with epilepsy and ID (Table 5) [16, 40]. The assessment process should adopt a person-centered approach and aim to identify whether changes in behavior or psychiatric symptoms are directly related to the epilepsy or influenced by its management.

Table 3

Potential neuropsychiatric effects of AEDs (adapted from Schmitz, 2006 [31]).

\begin{tabular}{|c|c|}
\hline Phenobarbitone & Irritability, aggression ${ }^{2}$ \\
\hline Phenytoin & $\begin{array}{l}\text { Schizophrenia-like psychosis (high serum concentrations), } \\
\text { encephalopathy }\end{array}$ \\
\hline Ethosusuximide & Psychosis (forced-normalization (FN)) \\
\hline Garbamazepine & Affective problems (mania) \\
\hline Valproate & Encephalopathy \\
\hline Vigabatrin & $\begin{array}{l}\text { Behavioral problems (agitation, aggression, hyperkinesia)". } \\
\text { psychosis }\end{array}$ \\
\hline Lamotrigine & Insomnia-anxiety \\
\hline Gabapentin & Behavioral problems ${ }^{2}$ \\
\hline Topiramate & $\begin{array}{l}\text { Psychosis (FN/seizure freedom), affective disturbance } \\
\text { (depression) }\end{array}$ \\
\hline Levetiracetam & Psychosis, depression, aggression ${ }^{2}$ \\
\hline Zonisamide & Affective problems, psychosis \\
\hline Lacosamide & Behavioral problems \\
\hline Perampanel & Aggression $^{2}$ \\
\hline
\end{tabular}

\footnotetext{
a Specific evidence in population with ID.
}

It is important to exclude potentially reversible causes of new onset psychiatric symptoms in people with epilepsy. These include delirium, which typically has a fluctuating course, inattention, and disordered thinking 
or altered level of consciousness. Delirium can be precipitated by infections, metabolic disturbances, toxins, hypoxia, urinary retention, and constipation [42]. Nonconvulsive status epilepticus can cause behavioral change as well as altered awareness, and there should be a low threshold for requesting an electroencephalogram (EEG) and/or considering a trial of benzodiazapines if this is considered. Other diagnoses to consider include alcohol and illicit drugs, limbic encephalitis, and neurodegenerative diseases [42]. Depending on the initial assessment, blood tests and/or brain imaging might be necessary if some of these conditions are suspected.

Table 4

AED effects on behavior in the population with ID (adapted from Copeland et aL, 2017 [36]).

\begin{tabular}{|c|c|c|}
\hline AED & Study & Effect \\
\hline \multirow[t]{4}{*}{ Lamotrigine } & $\begin{array}{l}\text { Mckee et al., } \\
2003\end{array}$ & $\begin{array}{l}\text { Improvement in stereotypy and lethargy } \\
\text { Adverse events included emotional } \\
\text { change }\end{array}$ \\
\hline & Mckee et al., & Improvements in all areas of the \\
\hline & 2006 & Aberrant Behavior Checklist $(\mathrm{ABC})^{\mathrm{a}}$ \\
\hline & $\begin{array}{l}\text { Sunder et al. } \\
2006\end{array}$ & $\begin{array}{l}\text { Significant improvement in stereotypy, } \\
\text { hyperactivity, lethargy, and } \\
\text { inappropriate speech on } A B C \text { in } \\
\text { community sample. }\end{array}$ \\
\hline $\begin{array}{l}\text { Lamotrigine and } \\
\text { Gabapentin }\end{array}$ & $\begin{array}{l}\text { Crawford et al. } \\
2001\end{array}$ & Reduction in challenging behavior \\
\hline \multirow[t]{2}{*}{ Topiramate } & Kerr et al., 2005 & $\begin{array}{l}\text { No significant change in behavior } \\
\text { compared to placebo }\end{array}$ \\
\hline & $\begin{array}{l}\text { Martin et al. } \\
2009\end{array}$ & $\begin{array}{l}\text { ABC-small improvements in major } \\
\text { behavioral areas }\end{array}$ \\
\hline Levetiracetam & $\begin{array}{l}\text { Helmstaedter } \\
\text { et al., } 2008\end{array}$ & $\begin{array}{l}\text { More negative side effects in people with } \\
\text { ID vs general population } \\
\text { Behavioral changes across sample }\end{array}$ \\
\hline \multirow[t]{2}{*}{ Perampanel } & $\begin{array}{l}\text { Shankar et al. } \\
2017\end{array}$ & $\begin{array}{l}\text { Behavioral and adverse mental heal th } \\
\text { effects - aggression, agitation, disruptive } \\
\text { behavior, depression, anxiety, mood } \\
\text { swings } \\
\text { Linked to previous psychiatric history }\end{array}$ \\
\hline & $\begin{array}{l}\text { Andres et al., } \\
2017\end{array}$ & Behavioral adverse effects - aggression \\
\hline
\end{tabular}

a $\mathrm{ABC}$ - Aberrant Behavior Checklist - a scale devised to assess treatment effects in people with $\mathrm{ID}[37]$. 


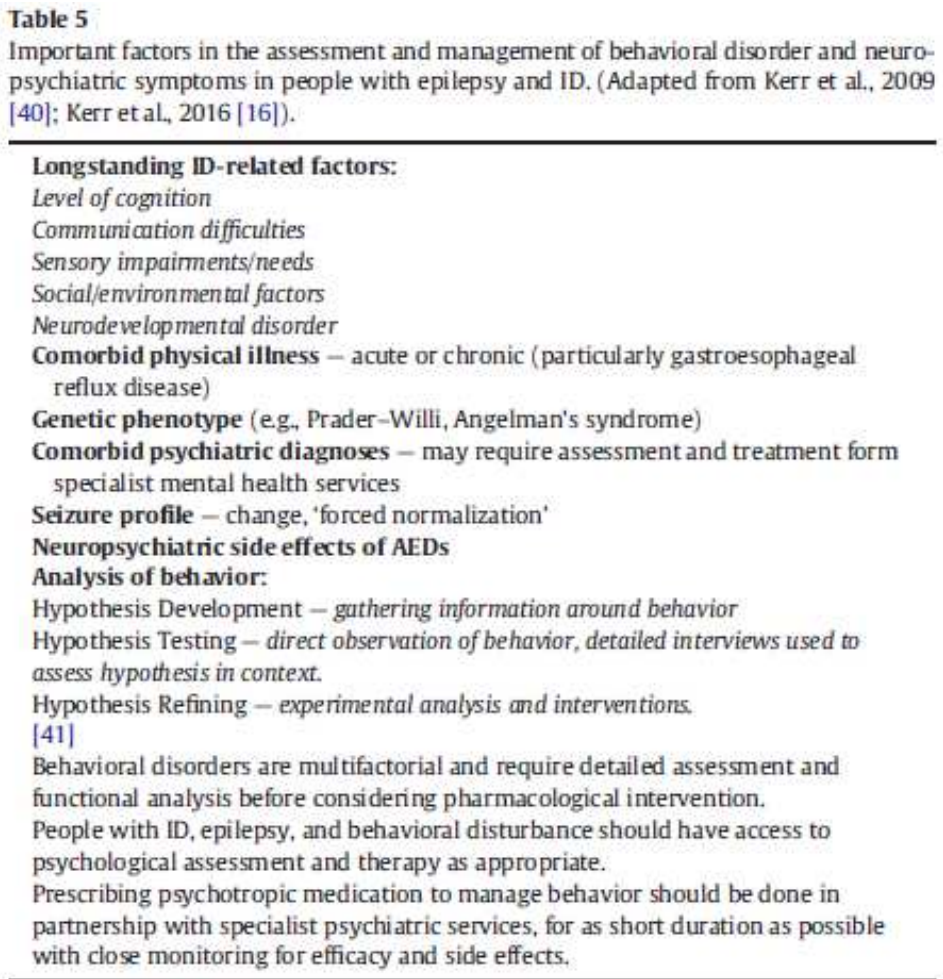

3.1.1. Defining the behavior

A video-EEG can be useful for people with epilepsy and ID to help differentiate seizure activity from behavior [43]. This, along with detailed information gathering and observations, will help discriminate seizures from other complex behaviors or stereotyped movements [44].

3.1.2. Psychiatric symptoms in people with an intellectual disability

The presentation of psychiatric symptoms in the population with ID can be complex and as heterogeneous as the population itself. This complexity may be increased by common comorbidities including neurodevelopmental disorders such as autism. The presence of communication difficulties alters our approach to assessment and diagnosis, and may diminish reliability. Therefore, attempting to apply objective and subjective diagnostic criteria to psychiatric symptoms is not straight forward.

In order to fully understand behavior, a detailed functional analysis may be required. This process will often require the input of specialist multidisciplinary learning disability teams to provide a holistic approach. This process is inevitably longer but needs to take into account all potential variables that may influence behavior and symptoms including environmental, social, sensory, emotional, and biological factors. Work may be required from a number of specialists from within the team including speech and language therapy, occupational therapy, nursing, and psychology in order to reach an accurate formulation of any individual's needs. There are specific evidence-based adapted diagnostic criteria available for people with ID that may help with the assessment process [45].

Following this assessment there will be a clearer indication as to whether the behavior is related to seizures, epilepsy treatment, or other factors (Table 5). There are validated tools available to help inform the assessment process including the Aberrant Behavior Checklist (ABC) [46].

\subsection{Treatment}

The NICE clinical guidelines on epilepsies (CG137) [17] suggest the same treatment for people with ID as the general population. However, there is no clear guidance on the specific complexities associated with epilepsy and ID. The Royal College of Psychiatrists has produced a technical paper advising on the prescription of AEDs in epilepsy for people with ID [47], based on current evidence. The College Report also includes considerations around the treatment of psychiatric comorbidities.

\subsubsection{AED-related neuropsychiatric symptoms}


The consensus guidelines [40] produced by the Health Special Interest Group of the International association for the Scientific Study of Intellectual Disability (IASSIDD), on the management of epilepsy in adults with ID, consider the impact of AEDs on behavior and cognition a priority. It is recommended that prior to the introduction of an AED, baseline assessments of behavior and cognition are completed, using validated tools, for later comparison [48].

Some AEDs have neuropsychiatric side effect profiles (see Table 5), and these should be borne in mind before they are prescribed to people with epilepsy and ID. For example phenobarbitone, phenytoin, and topiramate have been shown to have adverse effects upon cognition,

which is particularly relevant for people with ID [49]. Prescribing older AEDs including phenobarbitone and phenytoin is not advised for people with ID [47].

The prescription of multiple AEDs, at high doses, with rapid titration, is associated with an increased risk of adverse cognitive and behavioural effects [50]; AEDs should therefore be prescribed at the lowest possible dose with slow titration. This will help accurate assessment of efficacy and side effects. Slow titration will help identify the minimal therapeutic dose. If considering adding a new AED to treatment, it is advisable to do so before withdrawing the old AED. This will help assess the cause for changes in seizure control and side effect profile [47].

For individuals with particular risk factors including previous psychiatric history, history of behavioral disturbance, treatment-resistant epilepsy, and family history of psychiatric disorders, there should be close monitoring for the emergence of neuropsychiatric symptoms.

These symptoms may emerge during any change in AED medication, if withdrawing AEDs with mood stabilizing effect (carbamazepine, oxcarbazepine, valproate, lamotrigine), or if seizure freedom is achieved [50].

\subsubsection{Interictal psychiatric comorbidity}

The treatment of interictal psychiatric manifestations including depression, anxiety disorders, and psychotic illness will follow guidelines as advised for the general population. However, there are some specific considerations for people with epilepsy and ID. Psychological therapies, for example, may need to be adapted and tailored specifically to an individual's level of understanding and communication. The evidence for the use of psychological therapies for people with epilepsy and ID is limited with no randomized controlled trials available [35]. There is evidence to support the use of tailored cognitive behavioral therapy (CBT) in people with ID for the treatment of anxiety, depression, and psychosis [16]. Prior to the initiation of any therapy a 'step-wise' approach with formal neuropsychological and metacognitive assessment is recommended. This will help to gain a baseline understanding of cognitive ability, skills, emotional regulation, and insight, all aspects relevant to successful CBT [51].

\subsubsection{Pharmacological management}

3.2.3.1. Depression. If a depressive disorder is considered then the first step may be referral to specialist mental health services for assessment and diagnosis. The first line management of a depressive disorder may include supportive therapy and consideration for psychological therapy such as CBT where available [16]. If it is established that the depressive episode warrants pharmacological treatment then selective serotonin reuptake inhibitors (SSRIs) are considered first line therapy. Serotonin norepinephrine reuptake inhibitors (SNRIs) have also been shown be have no detrimental impact on seizure control at therapeutic doses. Older agents such as the tricyclic antidepressant clomipramine may reduce the seizure threshold [52]. There appears to be a dose-dependent relationship between the prescription of antidepressants and seizures. Therefore when prescribing, it is advised to start at a low dose with slow titration. When considering which SSRI to prescribe, it may be advised to consider alternatives to fluoxetine such as citalopram or sertraline. This is because fluoxetine has a long half-life and is associated with more drug interactions [47].

3.2.3.2. Psychosis. The treatment of interictal psychosis or psychotic disorders such as schizophrenia should follow usual treatment pathways as for the general population. It is well-understood that antipsychotic medications have the propensity to impact upon seizure control. In particular chlorpromazine and clozapine have been shown to demonstrate proconvulsive effects in patients with epilepsy [53]. Clozapine can cause epileptiform EEG changes and seizures even at therapeutic doses [54]. Rapid titration and high dose of clozapine may be the most detrimental to good seizure management [12]. A study examining the influence of antipsychotic drugs on seizures has highlighted that first generation antipsychotics have a slighter higher association with seizure risk. Among the second generation antipsychotic drugs, Clozapine has been associated with the highest incidence of seizures when compared with placebo, followed by olanzapine and then 
quetiapine [52]. Aripiprazole may have the lowest potential to induce seizures, and is worth considering first, if seizure control is paramount [55].

\subsubsection{Behavioral disorders}

Behavioral assessment and intervention should form a core component of the management of a behavioral disorder according to NICE guideline NG11 [56]. A randomized, single-blind, controlled trial of specialist behavior therapy for challenging behavior in people with ID showed significant improvement in $A B C$ scores and other measures of behavior [57]. Given the complexity of presentation of behavioral disorders in people with epilepsy and ID, this process would be best shared with specialist ID psychiatrist services [16].

\subsubsection{Pharmacological management}

There is limited evidence to support using psychotropic medications to treat challenging behavior in people with ID. A randomized controlled trial assessing the efficacy of risperidone and haloperidol in the treatment of aggression in people with ID showed no benefit compared with placebo [58]. Despite this, a large proportion of people with ID are Treated with antipsychotic medication for challenging behaviour without a diagnosis of serious mental illness [59].

When psychotropicmedication for behavioral disturbances is necessary then prescription and monitoring should be done in liaison with specialist psychiatric services. The prescription of antipsychotic cmedication for challenging behavior should be short-term and monitored for efficacy. Target behaviors should be identified from the outset for treatment and monitored considering the multifactorial nature of behaviour [16]. As discussed, concerns will remain over the potential impact of the prescribed psychotropic medications on seizure control.

\subsubsection{Periictal disturbance and postictal psychosis}

Fear and anxiety can also be associated with seizures themselves either in the preictal or ictal period. Differentiation between these two presentations can be difficult but is important in terms of treatment decisions [12].

Postictal psychosis can severely affect quality of life and pose particular difficulties in management. Classically a postictal psychosis is observed after a symptom-free period following the seizure. This time lag can be anything from hours to seven days [60]. This disturbance is usually relatively short-lived; however, prolonged debilitating presentations may warrant antipsychotic treatment. The antipsychotic can then be reduced and discontinued gradually following improvement in symptoms [50]

Improvement in seizure control will help reduce the likelihood of further postictal events, and so, treatment should be maximized. However, with seizure freedom comes the risk of so-called 'forced-normalization'. This is a risk of developing potentially severe psychotic and affective symptoms with seizure remission in patients with complex treatment-resistant epilepsy. This may be more likely with certain AEDs and should be managed as with interictal disturbances [60].

4. Delivery of care - the role of the neurologist

Epilepsy in people with ID is managed by various healthcare professionals including primary care physicians, specialist nurses, neurologists, psychiatrists, and neuropsychiatrists. Care pathways vary both within and between countries with limited guidance as to the appropriate care pathway for individuals. In the UK, multidisciplinary teams for people with ID tend to be based in the community where as neurological services tend to be hospital based. Two studies of English patients with learning disability and epilepsy found that around $40 \%$ received care for their epilepsy from a hospital-based neurology service [61,62]. People with ID and epilepsy managed primarily by neurologists had more neurological

comorbidities while those managed by community ID teams had more psychiatric comorbidity [62].

Most neurologists with an interest in epilepsy will see patients with ID and should therefore be aware of the spectrum of psychiatric comorbidities in this population, how to screen for them, avoid them, and treat if appropriate. Neurologists may have the best skills to exclude and or diagnose other underlying conditions that can cause psychiatric features, e.g., limbic encephalitis or neurodegenerative disorders. Neurologists should also be able to manage psychiatric side effects of AEDs. 
Neurologists may lack specific training and competence in managing significant psychiatric comorbidities in epilepsy. A recent survey highlighted a lower level of self-perceived knowledge and confidence in dealing with psychiatric comorbidities and epilepsy when comparing neurologists to psychiatrists [63]. In the same survey only just over $20 \%$ of adult neurologists felt their knowledge of epilepsy and ID was good or very good compared with $70 \%$ of psychiatrists. Given this, it may be appropriate that patients with more complicated or severe psychiatric comorbidities are managed by psychiatrists/neuropsychiatrists.

There is clearly therefore a need for greater support of neurologists both in terms of training and direct support form psychological services. This notwithstanding the neurologist has a current and important role in managing psychiatric comorbidities. This role can be divided into three areas of expertise. These three areas we describe below.

Competency A. The neurologist and the assessment of psychiatric comorbidities.

All neurologists should have the competency to identify the presence, or the suspicion of the presence of psychiatric disturbance, such as nonconvulsive status, infection, metabolic or toxic causes. Following this all neurologists should have the competency to

refer for further psychiatric assessment or manage as in competencies

$\mathrm{B}$ and $\mathrm{C}$ below.

Competency B. The neurologist managing epilepsy-related psychiatric comorbidities.

Following identification of epilepsy-related psychiatric comorbidity all neurologists will have the competency to alter AED medication if needed and to assess treatment options to reduce seizures or to manage neuropsychiatric side effects.

Competency in managing postictal psychiatric symptoms will depend on training and experience. Where needed referral to psychiatric services should occur.

Competency $\mathbf{C}$. The treatment of psychiatric comorbidity. This is again an area for personal skill and experience. Many neurologists have experience in treating depression for example. However, most neurologists lack the skills necessary to treat psychosis and behavioral

disturbance. The nature of psychiatric comorbidity, particularly challenging behavior needs the input of a multidisciplinary team. In this context, the neurologist best works as a source of guidance and skills to the team.

\section{Conclusions}

Psychiatric symptoms and behavioral disturbance are common in patients with epilepsy and ID and can be related to the epilepsy, epilepsy treatment, or other conditions or can occur as comorbid conditions. Careful assessment of psychiatric symptoms and behavioral disturbance are necessary to work out their etiology. Structured multidisciplinary assessment techniques can be a useful adjunct due to the complexity or etiology and comorbidities. Neurologists have a role in the multidisciplinary management of patients with ID and epilepsy with psychiatric comorbidities. Neurologist's skills may be particularly suited to screening for other conditions that may cause psychiatric symptoms, managing seizures, and changing AEDs if necessary. It might be more appropriate however for psychiatrists to advise on or manage psychiatric comorbidities, particularly if treatment with antipsychotic medication is warranted.

Conflicts of interest

The authors report no relationships that could be construed as a conflict of interest.

\section{References}

[1] Robertson J, Hatton C, Emerson E, Baines S. Prevalence of epilepsy among people with intellectual disabilities: a systematic review. Seizure Eur J Epilepsy Jul 1 2015;29:46-62.

[2] Keezer MR, Sisodiya SM, Sander JW. Comorbidities of epilepsy: current concepts and future perspectives. Lancet Neurol Jan 1 2016;15(1):106-15.

[3] Tellez-Zenteno JF, Patten SB, Jetté N,Williams J,Wiebe S. Psychiatric comorbidity in epilepsy: a population-based analysis. Epilepsia Dec 1 2007;48(12):2336-44.

[4] Ottman R, Lipton RB, Ettinger AB, Cramer JA, Reed ML, Morrison A, et al. Comorbidities of epilepsy: results from the epilepsy comorbidities and health (EPIC) survey. Epilepsia Feb 1 2011;52(2):308-15.

[5] Gaitatzis A, Carroll K, Majeed A, Sander JW. The epidemiology of the comorbidity of epilepsy in the general population. Epilepsia Dec 1 2004;45(12):1613-22. 
[6] Rai D, Kerr MP, McManus S, Jordanova V, Lewis G, Brugha TS. Epilepsy and psychiatric comorbidity: a nationally representative population-based study. Epilepsia 2012;

53(6):1095-103.

[7] Ettinger A, Reed M, Cramer J. Depression and comorbidity in community-based patients with epilepsy or asthma. Neurology Sep 28 2004;63(6):1008-14.

[8] Ettinger AB, ReedML, Goldberg JF, Hirschfeld RM. Prevalence of bipolar symptoms in epilepsy vs other chronic health disorders. Neurology Aug 23 2005;65(4):535-40.

[9] Cooper SA, Smiley E, Morrison J, Williamson A, Allan L. Mental ill-health in adults with intellectual disabilities: prevalence and associated factors. Br J Psychiatry Jan 1 2007;190(1):27-35.

[10] Turky A, Felce D, Jones G, KerrM. A prospective case control study of psychiatric disorders in adults with epilepsy and intellectual disability. Epilepsia Jul 1 2011;52(7):

1223-30.

[11] Bowley C, Kerr M. Epilepsy and intellectual disability. J Intellect Disabil Res Oct 1 2000;44(5):529-43.

[12] Torta R, Keller R. Behavioral, psychotic, and anxiety disorders in epilepsy: etiology, clinical features, and therapeutic implications. Epilepsia Oct 1999;40(s10):1.

[13] van Ool JS, Snoeijen-Schouwenaars FM, Schelhaas HJ, Tan IY, Aldenkamp AP, Hendriksen JG. A systematic review of neuropsychiatric comorbidities in patients with both epilepsy and intellectual disability. Epilepsy Behav Jul 1 2016;60:130-7.

[14] Espie CA, Watkins J, Curtice L, Espie A, Duncan R, Ryan JA, et al. Psychopathology in people with epilepsy and intellectual disability; an investigation of potential explanatory variables. J Neurol Neurosurg Psychiatry Nov 1 2003;74(11):1485-92.

[15] Arshad S, Winterhalder R, Underwood L, Kelesidi K, Chaplin E, Kravariti E, et al. Epilepsy and intellectual disability: does epilepsy increase the likelihood of co-morbid psychopathology? Res Dev Disabil Jan 1 2011;32(1):353-7.

[16] Kerr M, Linehan C, Brandt C, Kanemoto K, Kawasaki J, Sugai K, et al. Behavioral disorder in people with an intellectual disability and epilepsy: a report of the intellectual disability task force of the neuropsychiatric commission of ILAE.

Epilepsia Open Dec 1 2016;1(3-4):102-11.

[17] NICE clinical guideline 137. The epilepsies: the diagnosis and management of the epilepsies in adults and children in primary and secondary care; 2012.

[18] Davies R, Baxendale S, Thompson P, Duncan JS. Epilepsy surgery for people with a low IQ. Seizure Eur J Epilepsy Mar 1 2009;18(2):150-2.

[19] Bjørnæs H, Stabell KE, Heminghyt E, Røste GK, Bakke SJ. Resective surgery for intractable focal epilepsy in patients with low IQ: predictors for seizure control and outcome with respect to seizures and neuropsychological and psychosocial functioning. Epilepsia Feb 1 2004;45(2):131-9.

[20] McGrother CW, Bhaumik S, Thorp CF, Hauck A, Branford D, Watson JM. Epilepsy in adults with intellectual disabilities: prevalence, associations and service implications. Seizure Eur J Epilepsy Sep 1 2006;15(6):376-86.

[21] Lowe K, Allen D, Jones E, Brophy S,Moore K, JamesW. Challenging behaviours: prevalence and topographies. J Intellect Disabil Res Aug 1 2007;51(8):625-36.

[22] Powis L, Oliver C. The prevalence of aggression in genetic syndromes: a review. Res Dev Disabil May 1 2014;35(5):1051-71.

[23] Andrews TM, Everitt AD, Sander JW. A descriptive survey of long-term residents with epilepsy and intellectual disability at the Chalfont Centre: is there a relationship between maladaptive behaviour and magnetic resonance imaging findings? J Intellect Disabil Res Dec 1 1999;43(6):475-83.

[24] Tyrer F, McGrother CW, Thorp CF, Donaldson M, Bhaumik S, Watson JM, et al. Physical aggression towards others in adults with learning disabilities: prevalence and associated factors. J Intellect Disabil Res Apr 1 2006;50(4):295-304.

[25] Matson JL, Shoemaker M. Intellectual disability and its relationship to autism spectrum disorders. Res Dev Disabil Nov 1 2009;30(6):1107-14.

[26] McDermott S, Moran R, Platt T, Wood H, Isaac T, Dasari S. Prevalence of epilepsy in adults with mental retardation and related disabilities in primary care. Am J Ment Retard Jan 2005;110(1):48-56. 
[27] McClintock K, Hall S, Oliver C. Risk markers associated with challenging behaviours in people with intellectual disabilities: a meta-analytic study. J Intellect Disabil Res Sep 1 2003;47(6):405-16.

[28] Baghdadli A, Pascal C, Grisi S, Aussilloux C. Risk factors for self-injurious behaviours among 222 young childrenwith autistic disorders. J Intellect Disabil Res Nov 1 2003; 47(8):622-7.

[29] Smith KR, Matson JL. Behavior problems: differences among intellectually disabled adults with co-morbid autism spectrum disorders and epilepsy. Res Dev Disabil

Sep 1 2010;31(5):1062-9.

[30] Smith KR, Matson JL. Psychopathology: differences among adults with intellectually disabled, comorbid autism spectrum disorders and epilepsy. Res Dev Disabil May 1 2010;31(3):743-9.

[31] Schmitz B. Effects of antiepileptic drugs on mood and behavior. Epilepsia Nov 1 2006;47(s2):28-33.

[32] Kwan P, Brodie MJ. Early identification of refractory epilepsy. N Engl J Med Feb 3 2000;342(5):314-9.

[33] Marson AG, Appleton R, Baker GA, Chadwick DW, Doughty J, Eaton B, et al. A randomised controlled trial examining the longer-term outcomes of standard versus new antiepileptic drugs. The SANAD trial. Health Technol Assess Southampt

Oct 1 2007;11(37).

[34] Stephen LJ,Wishart A, BrodieMJ. Psychiatric side effects and antiepileptic drugs: observations from prospective audits. Epilepsy Behav Jun 1 2017;71:73-8.

[35] Beavis J, Kerr M, Marson AG, Dojcinov I. Pharmacological interventions for epilepsy in people with intellectual disabilities. Cochrane Database Syst Rev 2007(3):

CD005399.

[36] Copeland L, Meek A, Kerr M, RoblingM, Hood K,McNamara R. Measurement Copeland L, Meek A, Kerr M, RoblingM, Hood K,McNamara R. Measurement of side effects of anti-epileptic drugs (AEDs) in adults with intellectual disability: a systematic review. Seizure Eur J Epilepsy Oct 1 2017;51:61-73.

[37] AmanMG, Singh NN, Stewart AW, Field CJ. The aberrant behavior checklist: a behavior rating scale for the assessment of treatment effects. Am J Ment Defic 1985.

[38] Muzina DJ, Calabrese JR. Maintenance therapies in bipolar disorder: focus on randomized controlled trials. Aust N Z J Psychiatry Aug 2005;39(8):652-61.

[39] Berlin RK, Butler PM, PerloffMD. Gabapentin therapy in psychiatric disorders: a systematic review. The primary care companion for CNS disorders. 2015;17(5).

[40] Kerr M, Scheepers M, Arvio M, Beavis J, Brandt C, Brown S, et al. Consensus guidelines into the management of epilepsy in adults with an intellectual disability. J Intellect Disabil Res Aug 1 2009;53(8):687-94.

[41] KerrM, Gil-Nagel A, Glynn M, MulaM, Thompson R, Zuberi SM. Treatment of behavioral problems in intellectually disabled adult patients with epilepsy. EpilepsiaMar 1

2013;54(s1):34-40.

[42] Maguire M, Singh J, Marson A. Epilepsy and psychosis: a practical approach. Pract Neurol 2018;18:106-14.

[43] Detoledo JC, Lowe MR, Haddad H. Behaviors mimicking seizures in institutionalized individuals with multiple disabilities and epilepsy: a video-EEG study. Epilepsy Behav Jun 1 2002;3(3):242-4.

[44] Paul A. Epilepsy or stereotypy? Diagnostic issues in learning disabilities. Seizure Eur J Epilepsy Apr 1 1997;6(2):111-20.

[45] Cooper SA. The diagnostic criteria for psychiatric disorders for use with adults with learning disabilities/mental retardation (DC-LD) papers. J Intellect Disabil Res Sep 2003;47:1-2.

[46] Kerr MP. Behavioral assessment in mentally retarded and developmentally disabled patients with epilepsy. Epilepsy Behav Dec 1 2002;3(6):14-7.

[47] Royal College of Psychiatrists. The management of epilepsy in adults with intellectual disability, college report (CR203). Royal College of Psychiatrists; 2017.

[48] Kerr MP, Espie CA. Learning disability and epilepsy. I, towards common outcome measures. Seizure Oct 1 1997;6(5):331-6. 
[49] Aldenkamp A, Besag F, Gobbi G, Caplan R, Dunn DW, Sillanpää M, et al. Adverse cognitive and behavioural effects of antiepileptic drugs in children. Epileptic DisordMay

2016;18(s1):1.

[50] Kerr MP, Mensah S, Besag F, De Toffol B, Ettinger A, Kanemoto K, et al. International consensus clinical practice statements for the treatment of neuropsychiatric conditions associated with epilepsy. Epilepsia Nov 1 2011;52(11):2133-8.

[51] Joyce T, Globe A, Moody C. Assessment of the component skills for cognitive therapy in adults with intellectual disability. J Appl Res Intellect Disabil Mar 1 2006;19(1):

17-23.

[52] Alper K, Schwartz KA, Kolts RL, Khan A. Seizure incidence in psychopharmacological clinical trials: an analysis of Food and Drug Administration (FDA) summary basis of approval reports. Biol Psychiatry Aug 15 2007;62(4):345-54.

[53] Alldredge BK. Seizure risk associated with psychotropic drugs: clinical and pharmacokinetic considerations. Neurology 1999;53(5 Suppl. 2):S68-75.

[54] Langosch JM, TrimbleMR. Epilepsy, psychosis and clozapine. HumPsychopharmacol Clin Exp Mar 1 2002;17(2):115-9.

[55] Wu CS, Wang SC, Yeh IJ, Liu SK. Comparative risk of seizure with use of first-and secondgeneration antipsychotics in patients with schizophrenia and mood disorders. J

Clin Psychiatry May 2016;77(5):e573-9.

[56] NICE Clinical Guideline. Challenging behaviour and learning disabilities: prevention and interventions for people with learning disabilities whose behaviour challenges.

NICE guideline [NG11]; May 2015.

[57] Hassiotis A, RobothamD, Canagasabey A, Romeo R, Langridge D, Blizard R, et al. Randomized, single-blind, controlled trial of a specialist behavior therapy team for challenging

behavior in adults with intellectual disabilities. Am J Psychiatry Nov 2009;

166(11):1278-85.

[58] Tyrer P, Oliver-Africano PC, Ahmed Z, Bouras N, Cooray S, Deb S, et al. Risperidone, haloperidol, and placebo in the treatment of aggressive challenging behaviour in patients with intellectual disability: a randomised controlled trial. Lancet Jan 5 2008;

371(9606):57-63.

[59] Sheehan R, Hassiotis A, Walters K, Osborn D, Strydom A, Horsfall L. Mental illness, challenging behaviour, and psychotropic drug prescribing in peoplewith intellectual disability: UK population based cohort study. BMJ Sep 1 2015;351:h4326.

[60] Kanner AM. Psychiatric comorbidities in epilepsy: should they be considered in the classification of epileptic disorders? Epilepsy Behav Nov 1 2016;64:306-8.

[61] Ring H, Zia A, Bateman N,Williams E, Lindeman S, Himlok K. Howis epilepsy treated in people with a learning disability? A retrospective observational study of 183 individuals. Seizure 2008;18:264-8.

[62] Wagner AP, Croudace TJ, Bateman N, PenningtonMW, Prince E, Redley M, et al. Clinical services for adults with an intellectual disability and epilepsy: a comparison of management alternatives. PLoS One 2017;12:e0180266.

[63] Mula M, Cavalheiro E, Guekht A, Kanner AM, Lee HW, Özkara Ç, et al. Educational needs of epileptologists regarding psychiatric comorbidities of the epilepsies: a descriptive quantitative survey. Epileptic Disord Jun 1 2017;19(2):178-85. https:// doi.org/10.1684/epd.2017.0915. 